\title{
Toxicity and Loss of Mitochondrial Membrane Potential Induced by Alkyl Gallates in Trypanosoma cruzi
}

\author{
Rogério Andréo, ${ }^{1}$ Luís Octávio Regasini, ${ }^{1}$ Maicon Segalla Petrônio, \\ Bruna Galdorfini Chiari-Andréo, ${ }^{2}$ Aline Tansini, ${ }^{2}$ \\ Dulce Helena Siqueira Silva, ${ }^{1}$ and Regina Maria Barretto Cicarelli ${ }^{2}$ \\ ${ }^{1}$ Instituto de Química, Universidade Estadual Paulista (UNESP), Rua Professor Franscisco Degni 55, Bairro Quitandinha, CP 355, \\ 14800-900 Araraquara, SP, Brazil \\ ${ }^{2}$ Faculdade de Ciências Farmacêuticas, Universidade Estadual Paulista (UNESP), Rodovia Araraquara-Jaú, km 1, CP 355, \\ 14801-902 Araraquara, SP, Brazil
}

Correspondence should be addressed to Regina Maria Barretto Cicarelli; cicarell@fcfar.unesp.br

Received 8 September 2014; Revised 18 December 2014; Accepted 22 December 2014

Academic Editor: Tzi Bun Ng

Copyright (C) 2015 Rogério Andréo et al. This is an open access article distributed under the Creative Commons Attribution License, which permits unrestricted use, distribution, and reproduction in any medium, provided the original work is properly cited.

\begin{abstract}
American trypanosomiasis or Chagas disease is a debilitating disease representing an important social problem that affects, approximately, 10 million people in the world. The main aggravating factor of this situation is the lack of an effective drug to treat the different stages of this disease. In this context, the search for trypanocidal substances isolated from plants, synthetic or semi synthetic molecules, is an important strategy. Here, the trypanocidal potential of gallates was assayed in epimastigotes forms of T. cruzi and also, the interference of these substances on the mitochondrial membrane potential of the parasites was assessed, allowing the study of the mechanism of action of the gallates in the T. cruzi organisms. Regarding the preliminary structure-activity relationships, the side chain length of gallates plays crucial role for activity. Nonyl, decyl, undecyl, and dodecyl gallates showed potent antitrypanosomal effect $\left(\mathrm{IC}_{50}\right.$ from 1.46 to $\left.2.90 \mu \mathrm{M}\right)$ in contrast with benznidazole $\left(\mathrm{IC}_{50}=34.0 \mu \mathrm{M}\right)$. Heptyl gallate showed a strong synergistic activity with benznidazole, reducing by $10^{5}$-fold the $\mathrm{IC}_{50}$ of benznidazole. Loss of mitochondrial membrane potential induced by these esters was revealed. Tetradecyl gallate induced a loss of $53 \%$ of the mitochondrial membrane potential, at $\mathrm{IC}_{50}$ value.
\end{abstract}

\section{Introduction}

Chagas disease (or American trypanosomiasis) was recognized by World Health Organization as one of thirteen neglected tropical diseases in the world [1]. It was estimated that over 10 million people are infected, and Latin America was considered the area of the highest prevalence [2]. This parasitic disease is caused by Trypanosoma cruzi (family, Trypanosomatidae and order, Kinetoplastida), a hemoflagellate protozoa [3], which can be found on several strains with different mechanisms of pathogenesis, immunogenicity, treatment response, and epidemiology [4]. The development of infection includes an acute phase which lasts up to six months after infection, an indeterminate phase with no symptoms, and a chronic phase in which approximately $30 \%$ of patients show clinical evidence of heart disease or megavisceras [5].

The current chemotherapy uses benznidazole, a nitroimidazole derivative, which is orally administered in acute phase and short-term chronic phase $[6,7]$. The usefulness of this drug is limited by its narrow therapeutic window and due to serious side effects, such as anorexia, nausea, headache, paresthesia, peripheral neuropathies, dermatitis, central nervous system (CNS) depression, and maniac symptoms [7, 8]. However, several parasite subpopulations with different host tissue's tropism contribute to the low clinical efficacy of this drug [9]. Therefore, there are efforts for the discovery and design of new therapeutic compounds to treat Chagas disease, due to the complexity of this disease. 
Gallic acid (3,4,5-trihydroxybenzoic acid) is a precursor of hydrolysable tannins in the biosynthesis that occurs in plants [10] and its natural and semisynthetic derivatives have been associated with a wide variety of biological activities, such as antiproliferative [11-13], chemopreventive [14], antihemolytic [15], antioxidant [16], and anti-inflammatory [17] activities. However, the main interest in gallic acid and in its derivatives has been associated with their antimicrobial properties. It has been shown that $n$-octyl gallate possesses fungicidal activity against Saccharomyces cerevisiae and Zygosaccharomyces bailii in any stage of their growth $[18,19]$. Leal and coworkers reported the potent fungitoxicity of n-nonyl gallate against yeasts, dermatophytes, and hialohyphomycetes [20]. Lauryl gallate showed antibacterial activity against Gram-positive bacteria, including methicillinresistant Staphylococcus aureus (MRSA) [21, 22].

Thus, the aim of this study was to investigate the antitrypanosomal activity of gallic acid and its esters against epimastigote forms of Trypanosoma cruzi. Further analysis involving interactions generated by combinations between alkyl gallates and benznidazole was also carried out. In addition, the apoptosis-inducing activity by alkyl gallates was studied through the parasite mitochondrial membrane potential assay.

\section{Material and Methods}

2.1. Compounds. The compounds tested in this study were synthesized as described previously $[14,15]$.

\subsection{Parasites. Epimastigote forms of Trypanosoma cruzi of Y} strain, described by Silva and Nussenzweig (1953) [23], which is considered a standard strain of type I, were grown in LIT media (liver infusion tryptose media) at $28^{\circ} \mathrm{C}$ [24].

2.3. Cytotoxicity Assay Using MTT. The cytotoxicity assay with epimastigotes T. cruzi was performed using the MTT colorimetric method as described by Muelas-Serrano et al. (2000) [25] with modifications described in Cotinguiba et al. (2009) [26]. The parasites were treated with different concentrations of the substances for 72 hours and then, the parasite viability was estimated by measuring the absorbance at $595 \mathrm{~nm}$. The concentration versus response curve was constructed to enable the determination of $\mathrm{IC}_{50}$. An equation that describes the curve was obtained using Origin 7.0 software. Means and standard deviations were calculated. ANOVA and Tukey's tests were carried out when necessary. Differences in means were treated as significant when $P<$ 0.05 . Benznidazole was used as positive control $\left(\mathrm{IC}_{50}=\right.$ $34.0 \mu \mathrm{M})$.

2.4. Mitochondrial Membrane Potential Assay. The influence of the treatments with the gallates in the mitochondrial membrane potential was assessed. The parasites were treated with the substances during 72 hours using, as standard concentration, the $\mathrm{IC}_{50}$ previously determined by the MTT assay. The percentage of parasite cells which suffered loss in the mitochondrial membrane potential due to the treatment with the tested compounds was measured by flow cytometry using JC-1 dye (5,5',6,6' -tetrachloro-1,1',3,3' -tetraethylbenzimidazolcarbocyanine iodide, BD MitoScreen kit) according to the manufacturer's instruction $[27,28]$. A FacsCanto I cytometer was used, and the data were recorded and analyzed on the software of the equipment. Pentamidine was used as positive control, at $58.7 \mu \mathrm{M}$ for 24 -hour treatment.

\section{Results and Discussion}

The antitrypanosomal activity of a homologous series of alkyl gallates, gallic acid, and other analogues was evaluated against epimastigote forms of Trypanosoma cruzi. This study was carried out in order to correlate chemical characteristics of the molecules with the observed activity, including the importance of free hydroxyl groups and side chain length. Table 1 summarizes the $\mathrm{IC}_{50}$ values of these compounds.

Gallic acid (1) was found to be totally inactive against $T$. cruzi $\left(\mathrm{IC}_{50}>100 \mu \mathrm{M}\right)$ and its derivatives up to hexyl gallate $(2-7)$ exhibited similar $\mathrm{IC}_{50}$ values $\left(\mathrm{IC}_{50}>100 \mu \mathrm{M}\right)$. Heptyl gallate $\left(8, \mathrm{IC}_{50}=37.3 \pm 0.9\right)$ showed weak activity which increased in the case of longer carbon chain derivatives up to undecyl gallate $\left(12, \mathrm{IC}_{50}=1.46 \pm 0.0\right)$. However, the increase in the carbon chains, becoming bigger than undecyl gallate, led to lower activity, as shown for compounds $\mathbf{1 3}$ and $\mathbf{1 4}$ (Table 1). Such results indicate that the 3,4,5-trihydroxyphenyl moiety appeared to be necessary but not sufficient for antiprotozoal activity. On the other hand, Kubo et al. (2001) [18] verified that the length of the alkyl chain is not a major contributor but plays an important role in eliciting the activity of the gallates.

Among the thirteen tested gallates (2-14) esterified with linear alcohols from $\mathrm{C} 1$ to $\mathrm{C} 14$, best results were observed for esters with chain lengths ranging from 9 to 12, which present $C \log P$ values of $4.11-5.30$, as reported previously by Rosso et al. (2006) [16].

$n$-Undecyl gallate (12), the most active derivative, with $\mathrm{IC}_{50}$ of $1.46 \mu \mathrm{M}(C \log P=4.90)$, was twenty-three times more potent than benznidazole, used as positive control $\left(\mathrm{IC}_{50}=34.0 \mu \mathrm{M}\right)$. Such results indicate that esterification led to appearance of antitrypanosomal activity, suggesting that a free carboxyl group was not crucial for protozoal death. In contrast, esters with $C \log P$ values lower than 3.32 or higher than 0.92 exhibited lower potency than the positive control.

Altogether, there is a clear and positive correlation among $\mathrm{IC}_{50}$ values, alkyl chain length and its contribution to the lipophilicity, which are in agreement with previous studies of this homologous series $[19,29]$. Furthermore, the trypanocidal potential increased with the increase in the number of carbons found on the side chain until reaching the maximum activity, in this case at $n$-undecyl gallate (12), and longer carbon chains showed lower trypanocidal activity, reaching a cutoff at $n$-tetradecyl gallate (14). If the homologs longer than 14 might show antitrypanosomal activity, their $\mathrm{IC}_{50}$ values will be superior at $17.6 \mu \mathrm{M}$, representing low potency, not corroborating for further chemical or biological investments.

In previous studies, the cutoff phenomenon was observed for alkanols, which was correlated with their amphipathic properties. In the case of alkyl gallates, their amphiphilicity appeared to be dependent on the presence of two 
TABLE 1: Antitrypanosomal activity of gallic acid (1) and $n$-alkyl gallates (2-14) against epimastigote forms of Trypanosoma cruzi. $\mathrm{IC}_{50}$ values were expressed in $\mu \mathrm{M}$.

\begin{tabular}{lccc}
\hline Compound & $\mathrm{R}$ & $\mathrm{Clog} P^{\mathrm{a}}$ & $\mathrm{IC}_{50}$ \\
\hline Gallic acid (1) & $\mathrm{H}$ & 0.89 & $>100^{\mathrm{b}}$ \\
Methyl gallate (2) & $\mathrm{CH}_{3}$ & 0.92 & $>100^{\mathrm{b}}$ \\
Ethyl gallate (3) & $\mathrm{CH}_{2} \mathrm{CH}_{3}$ & 1.27 & $>100^{\mathrm{b}}$ \\
Propyl gallate (4) & $\left(\mathrm{CH}_{2}\right)_{2} \mathrm{CH}_{3}$ & 1.73 & $>100^{\mathrm{b}}$ \\
Butyl gallate (5) & $\left(\mathrm{CH}_{2}\right)_{3} \mathrm{CH}_{3}$ & 2.13 & $>100^{\mathrm{b}}$ \\
Pentyl gallate (6) & $\left(\mathrm{CH}_{2}\right)_{4} \mathrm{CH}_{3}$ & 2.53 & $>100^{\mathrm{b}}$ \\
Hexyl gallate (7) & $\left(\mathrm{CH}_{2}\right)_{5} \mathrm{CH}_{3}$ & 2.92 & $>100^{\mathrm{b}}$ \\
Heptyl gallate (8) & $\left(\mathrm{CH}_{2}\right)_{6} \mathrm{CH}_{3}$ & 3.32 & $37.3 \pm 0.9$ \\
Octyl gallate (9) & $\left(\mathrm{CH}_{2}\right)_{7} \mathrm{CH}_{3}$ & 3.72 & $23.0 \pm 5.3$ \\
Nonyl gallate (10) & $\left(\mathrm{CH}_{2}\right)_{8} \mathrm{CH}_{3}$ & 4.11 & $2.90 \pm 0.1$ \\
Decyl gallate (11) & $\left(\mathrm{CH}_{2}\right)_{9} \mathrm{CH}_{3}$ & 4.51 & $1.50 \pm 0.3$ \\
Undecyl gallate (12) & $\left(\mathrm{CH}_{2}\right)_{10} \mathrm{CH}_{3}$ & 4.90 & $1.46 \pm 0.0$ \\
Dodecyl gallate (13) & $\left(\mathrm{CH}_{2}\right)_{11} \mathrm{CH}_{3}$ & 5.30 & $2.13 \pm 0.2$ \\
Tetradecyl gallate (14) & $\left(\mathrm{CH}_{2}\right)_{13} \mathrm{CH}_{3}$ & 6.09 & $17.6 \pm 1.8$ \\
Benznidazole & - & - & 34.0 \\
\hline
\end{tabular}

${ }^{a}$ Values described by Rosso and coworkers (2006) [16].

${ }^{\mathrm{b}}$ Percentage of inhibition at $100 \mu \mathrm{M}$.

${ }^{c}$ Positive control.

features: hydrophilic phenolic hydroxyls and hydrophobic alkyl chain. Fujita and Kubo (2002) [19] reported the antifungal activity of gallates, suggesting that these compounds possessed amphiphilic capacity and surfactant properties and they might act disrupting the fluidic bilayer membrane, leading to fungal death.

The synergistic effects of the combination using gallic acid and its esters with benznidazole, the antichagasic drug, were also evaluated. The definitions and mathematical determination of the formula for synergism were used as described by Hellmann et al. (2010) [30]. Briefly, the fractional inhibitory concentration (FIC) index was calculated by using the formula FIC index $=A / B+A / C$. In this formula, $A, B$, and $C$ were $\mathrm{IC}_{50}$ of gallate with benznidazole, $\mathrm{IC}_{50}$ of gallate alone, and $\mathrm{IC}_{50}$ of benznidazole alone, respectively. From this calculation, a FIC index $\leq 0.5$ was considered evidence of synergistic effect, as this value can be generated only if the concentrations of both compounds in combination do not exceed one-quarter of the $\mathrm{IC}_{50}$ of either drug tested alone. A FIC index $>4.0$ indicates antagonism. When tested alone, some gallates (2-7) have not led to a significant number of epimastigotes toxicity, even at the highest concentration tested $(100 \mu \mathrm{M})$. Therefore, to calculated FIC index for these compounds, the $\mathrm{IC}_{50}$ was arbitrarily defined as $50 \mu \mathrm{M}$ (Table 2).

The interactions between compounds 1-14 and benznidazole were highly variable, indicating dependence on the gallates chain length. Association between gallic acid (1) and short esters (2-4) with benznidazole was indifferent. Additive interaction was observed for inactive short esters (5 and $\mathbf{6})$ and most potent long esters, which exhibited FIC index values ranging from 0.560 to 0.765 . Interestingly, medium chain length gallates (7-9) and the long chain length ester 14 with
FIC index values bellow 0.257 exhibited synergism. The most significant synergistic effect was observed for heptyl gallate $(8, F I C=0.084)$, which reduced by $10^{5}$-fold the concentration of benznidazole necessary to inhibit cell growth in $50 \%\left(\mathrm{IC}_{50}\right.$ of $37.3 \pm 0.93 \mu \mathrm{M}$ ).

Synergism was observed at $\mu \mathrm{M}$ level, evidencing a strong antitrypanosomal activity and the potential of medium and long chain alkyl gallates as prototypes for further studies and development of novel therapeutic agents. It is also worth mentioning that the significant results from the association of benznidazole and alkyl gallates, which enabled the use of smaller doses of benznidazole, extended dosing intervals between consecutive administrations and short-term treatment leading to fewer and less intense side effects.

Few reports have been found on the antimicrobial synergistic effect against trypanosomatidae protozoa. Urbina and coauthors $(1988,1995,2002,2009)$ [31-34] described systematic studies involving antifungal drugs and their associations as trypanocidal combined agents for treatment of Chagas disease, such as azoles (ketoconazole and posaconazole) with mevinolin, terbinafine, aspirin, and amiodarone. Recently, the interaction between benznidazole and parthenolide was investigated against $T$. cruzi, which evidenced synergistic and additive activities against epimastigotes and trypomastigotes, respectively.

Additionally, trypanocidal gallates (8-14) were investigated for their influence on the mitochondrial membrane potential. Considering that the loss of mitochondrial membrane potential is a typical characteristic of apoptotic cells [35], it was used to elucidate a possible mode of parasite death. In living cells, JC- 1 dye crosses the plasmatic membrane as monomers, penetrating into the mitochondria. This process is controlled by the membrane potential of this organelle. The membrane of healthy mitochondria is polarized and JC-1 is rapidly internalized, increasing the concentration gradient, which may lead to its aggregation. In the flow cytometer, the JC-1 monomers were detected in the FL-1 channel (FITCS), while its aggregates were observed in the red channel FL2 (PE). On the other hand, injured mitochondria exhibits depolarized membrane and JC-1 remains in the cytoplasm as monomers. Then, we suggest that the cells which loss their mitochondrial membrane potential, which could be apoptotic cells, lose their fluorescence and could be captured in Q2 quadrant, whereas normal cells are detected in Q4 quadrant. Figure 1 presents the flow cytometry graphs.

Figure 1 presents the flow cytometry analysis of $n$-undecyl gallate (12) on T. cruzi.

Among the tested gallates, compounds $\mathbf{8}, \mathbf{9}$, and $\mathbf{1 4}$ promoted important loss in the mitochondrial membrane potential, which maybe an apoptosis-inducing activity, with percentage of cells with reduction of mitochondrial membrane potential of $46.6,43.6$, and 53.2 , respectively. The results are presented on Table 3 .

Figure 1(a) shows that untreated epimastigotes (control) did not lose their mitochondrial membrane potential which can be observed due to the high fluorescence detected in FL-2 channel (PE). Similarly, it is observed that $n$-undecyl gallate (12) (Figure 1(b)) did not stimulate this influence in the treated cells since it did not induce a reduction 


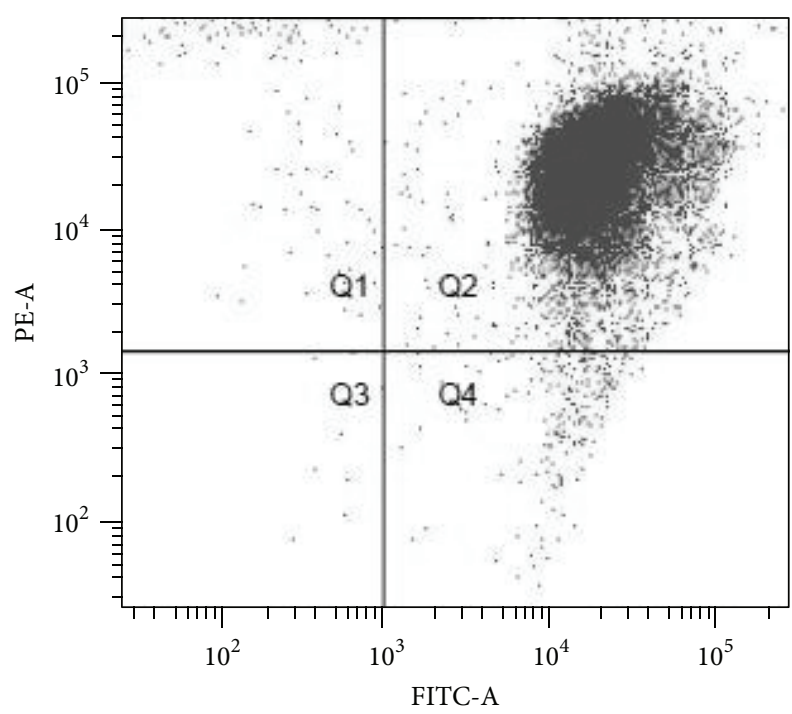

(a) Negative control

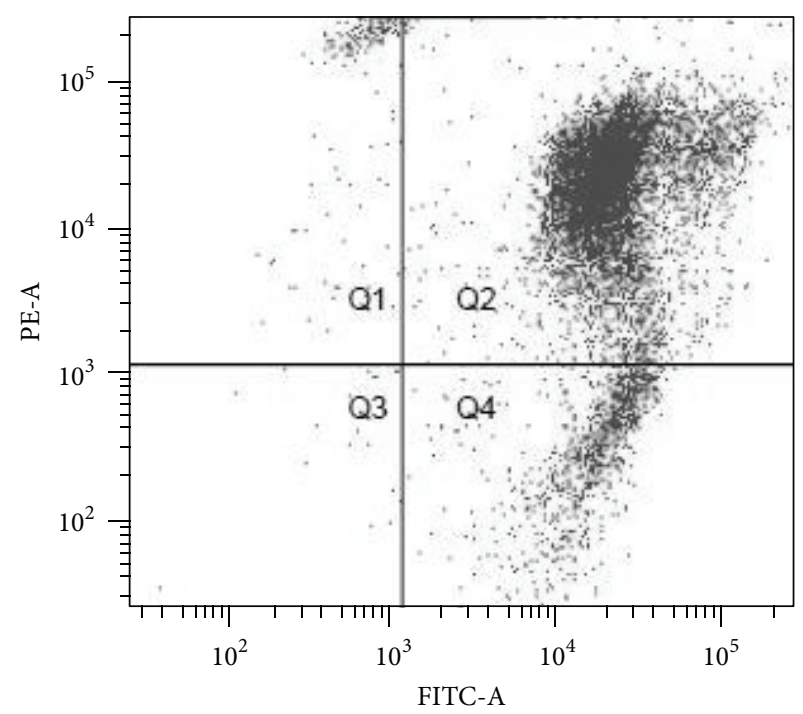

(b) $n$-Undecyl gallate (12)

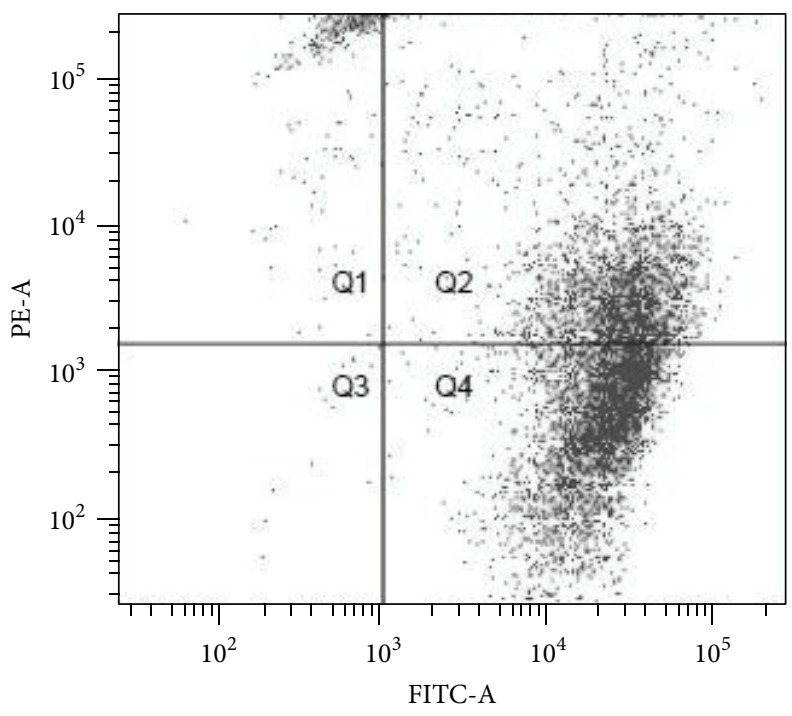

(c) Pentamidine

FIGURE 1: Flow cytometry analysis of epimastigotes forms of T. cruzi Y strain, without any treatment (a), treated with $1.46 \mu \mathrm{M}$ of $n$-Undecyl gallate (12) for $72 \mathrm{~h}(\mathrm{~b})$, and treated with $58.7 \mu \mathrm{M}$ of pentamidine for $24 \mathrm{~h}(\mathrm{c})$.

of fluorescence as shown by the control, suggesting the maintenance of the membrane potential. In contrast, the cells treated with pentamidine (Figure 1(c)) show intense decrease in the fluorescence represented by PE, suggesting a loss of mitochondrial membrane potential which may indicate apoptosis of the parasites analyzed. The results of flow cytometry for $n$-undecyl gallate (12) are presented on Table 3.

The results showed that the gallate esters used in this study induced loss of the mitochondrial membrane potential and maybe apoptosis in the parasites. This indicates that one of the mechanisms of cell death induced by the gallates activity could be similar to the apoptosis. This can be visualized by comparing the results with pentamidine, an apoptosisinducing drug [36], which led to different percentages of mitochondrial membrane potential relatively to the control.
The treatment with some gallates, such as the substances $\mathbf{8}, \mathbf{9}$, and $\mathbf{1 4}$, showed a percentage of loss of mitochondrial membrane potential similar to the pentamidine treatment.

Pentamidine is a dicationic drug which has been used in the last 50 years for the treatment of African trypanosomiasis and antimony-resistant leishmaniasis and is known to cause changes in mitochondrial metabolism [37]. The drug that can cause a collapse in mitochondrial membrane potential leads to an imbalance in intracellular $\mathrm{Ca}^{2+}$ [38]. Electronic microscopy transmission studies with cells treated with pentamidine showed condensation and disruption of kinetoplast DNA core and collapse of mitochondrial membrane [39, 40].

Based on the results obtained by the flow cytometry and cytotoxicity analysis, it is possible to infer that other mechanisms of action, different from apoptosis, might be associated with the death of the parasites, since the substances that 
TABLE 2: Synergism evaluation between hypothetical $\mathrm{IC}_{50}$ values used for calculation of FIC index.

\begin{tabular}{|c|c|c|c|c|}
\hline Compound & $\begin{array}{c}\mathrm{IC}_{50} \\
\text { (gallates } \\
\text { alone) }\end{array}$ & $\begin{array}{c}\mathrm{IC}_{50} \\
\text { (gallates with } \\
\text { benznidazole) }\end{array}$ & $\begin{array}{c}\text { FIC } \\
\text { index }\end{array}$ & $\begin{array}{c}\text { Interaction } \\
\text { type }\end{array}$ \\
\hline Gallic acid (01) & $294^{\mathrm{a}}$ & 17.4 & 2.017 & I \\
\hline $\begin{array}{l}\text { Methyl gallate } \\
(02)\end{array}$ & $271^{\mathrm{a}}$ & 15.3 & 1.786 & I \\
\hline $\begin{array}{l}\text { Ethyl gallate } \\
\text { (03) }\end{array}$ & $252^{\mathrm{a}}$ & 10.2 & 1.193 & I \\
\hline $\begin{array}{l}\text { Propyl gallate } \\
(\mathbf{0 4})\end{array}$ & $235^{\mathrm{a}}$ & 8.90 & 1.043 & I \\
\hline $\begin{array}{l}\text { Butyl gallate } \\
(05)\end{array}$ & $221^{\mathrm{a}}$ & 7.47 & 0.878 & A \\
\hline $\begin{array}{l}\text { Pentyl gallate } \\
\text { (06) }\end{array}$ & $208^{\mathrm{a}}$ & 6.02 & 0.708 & A \\
\hline $\begin{array}{l}\text { Hexyl gallate } \\
\text { (07) }\end{array}$ & $196^{\mathrm{a}}$ & 2.28 & 0.257 & S \\
\hline $\begin{array}{l}\text { Heptyl gallate } \\
(\mathbf{0 8})\end{array}$ & 37.3 & 0.64 & 0.084 & S \\
\hline $\begin{array}{l}\text { Octyl gallate } \\
(09)\end{array}$ & 6.49 & 0.62 & 0.165 & S \\
\hline $\begin{array}{l}\text { Nonyl gallate } \\
\text { (10) }\end{array}$ & 0.86 & 0.44 & 0.560 & A \\
\hline $\begin{array}{l}\text { Decyl gallate } \\
\text { (11) }\end{array}$ & 0.46 & 0.24 & 0.548 & A \\
\hline $\begin{array}{l}\text { Undecyl } \\
\text { gallate (12) }\end{array}$ & 0.47 & 0.32 & 0.716 & A \\
\hline $\begin{array}{l}\text { Dodecyl } \\
\text { gallate (13) }\end{array}$ & 0.72 & 0.51 & 0.765 & A \\
\hline $\begin{array}{l}\text { Tetradecyl } \\
\text { gallate (14) }\end{array}$ & 6.44 & 0.58 & 0.155 & S \\
\hline Benznidazole $^{\mathrm{b}}$ & 8.84 & - & - & - \\
\hline
\end{tabular}

${ }^{\mathrm{a}}$ Hypothetical $\mathrm{IC}_{50}$ value used for calculating of FIC index.

${ }^{\mathrm{b}}$ Positive control.

${ }^{*} \mathrm{I}, \mathrm{A}$, and $\mathrm{S}$ mean indifferent interaction, antagonism, and synergism, respectively.

caused more significant dysfunction in the mitochondrial membrane potential $(\mathbf{8}, \mathbf{9}$, and $\mathbf{1 4})$ are not the same substances that according to the cytotoxicity assay cause higher rates of parasites death $(10,11,12$, and 13$)$. In addition, maintenance of cell viability might be associated with low affinity or steric hindrance of the molecular target due to its physical-chemical properties.

Another possible mechanism of action of the gallic acid esters would be similar to the results found by Abe et al. (2000) [41]. These authors showed that some gallates are potent inhibitors of the enzyme squalene epoxidase, which is involved in the biosynthesis of ergosterol [42] and, therefore, is essential for the survival of the microorganism.

Ergosterol is essential to the parasite because it is the most abundant sterol found in the membrane of lower eukaryotes and is therefore found in fungi and parasitic protozoa such as Leishmania and Trypanosoma [43-46].

The inhibition of sterol biosynthesis is associated with the loss of cell membrane fluidity, which might lead to
TABLE 3: Loss of mitochondrial membrane potential (\%) of parasite cells.

\begin{tabular}{lccc}
\hline Compound & $\begin{array}{c}\text { Negative } \\
\text { control }\end{array}$ & $\begin{array}{c}\text { Parasite } \\
\text { treated with } \\
\text { gallates }\end{array}$ & $\begin{array}{c}\text { Positive } \\
\text { control }\end{array}$ \\
\hline Heptyl gallate (08) & 1.0 & 46.6 & 56.9 \\
Octyl gallate (09) & 1.0 & 43.6 & 56.9 \\
Nonyl gallate (10) & 1.0 & 5.9 & 56.9 \\
Decyl gallate (11) & 1.0 & 9.0 & 56.9 \\
Undecyl gallate (12) & 1.0 & 12.5 & 56.9 \\
Dodecyl gallate (13) & 1.0 & 13.4 & 56.9 \\
Tetradecyl gallate (14) & 1.0 & 53.2 & 56.9 \\
\hline
\end{tabular}

the parasite death through the same mechanism of action of commercial drugs, such as terbinafine [42].

Mitochondria are one of the first organelles to be affected after treatment of $T$. cruzi with ergosterol biosynthesis inhibitors, and even stronger effect may occur when an inhibitor of squalene epoxidase is used [36-47].

Due to the results of our experiments that demonstrated that there are changes in the mitochondrial membrane potential of the parasites when treated with gallates, we suggest that these compounds cause the parasite death by more than one pathway, which probably includes loss of mitochondrial membrane potential, correlated with the induction of apoptosis and, also, interfering in the biosynthesis of ergosterol in the parasites.

The phenol moiety is often associated with cytotoxic effects due to the possible free radical or reactive oxygen species formation, which might be deleterious to the parasite metabolism.

\section{Conclusions}

This study demonstrated that gallic acid is not very toxic to $T$. cruzi epimastigotes. However its esterification yielding gallate esters with different side chain lengths afforded compounds with strong trypanocidal potential, which is probably also due to a change in the mitochondrial membrane potential and an interference in the biosynthesis of ergosterol in the parasites [48]. It is important to clarify that previous studies demonstrate a correlation between epimastigote and trypomastigote forms of $T$. cruzi, the last one the infective form. Thus, this research encourages the development of new research aiming to apply the gallates as an alternative to current therapy against Chagas disease.

\section{Conflict of Interests}

The authors declare that there is no conflict of interests regarding the publication of this paper.

\section{Acknowledgments}

The authors acknowledge the financial support from the State of São Paulo Research Foundation (Fundação de Amparo 
à Pesquisa do Estado de São Paulo (FAPESP)), CNPq, PADC-FCF-UNESP, and Coordination for the Improvement of Higher Education Personnel (Capes, Coordenadoria de Aperfeiçoamento de Pessoal de Nível Superior) to this research.

\section{References}

[1] P. J. Hotez, D. H. Molyneux, A. Fenwick et al., "Control of neglected tropical diseases," The New England Journal of Medicine, vol. 357, no. 10, pp. 1018-1027, 2007.

[2] World Health Organization (WHO), 2010, http://www.who.int/ mediacentre/factsheets/fs340/en/.

[3] H. B. Tanowitz, L. V. Kirchhoff, D. Simon, S. A. Morris, L. M. Weiss, and M. Wittner, "Chagas' disease," Clinical Microbiology Reviews, vol. 5, no. 4, pp. 400-419, 1992.

[4] A. Prata, "Clinical and epidemiological aspects of Chagas disease," The Lancet Infectious Diseases, vol. 1, no. 2, pp. 92-100, 2001.

[5] S. S. Estani, E. L. Segura, A. M. Ruiz, E. Velazquez, B. M. Porcel, and C. Yampotis, "Efficacy of chemotherapy with benznidazole in children in the indeterminate phase of Chagas' disease," The American Journal of Tropical Medicine and Hygiene, vol. 59, no. 4, pp. 526-529, 1998.

[6] J. D. Maya, B. K. Cassels, P. Iturriaga-Vásquez et al., "Mode of action of natural and synthetic drugs against Trypanosoma cruzi and their interaction with the mammalian host," Comparative Biochemistry and Physiology Part A: Molecular \& Integrative Physiology, vol. 146, no. 4, pp. 601-620, 2007.

[7] J. R. Cançado, "Long term evaluation of etiological treatment of Chagas disease with benznidazole," Revista do Instituto de Medicina Tropical de São Paulo, vol. 44, no. 1, pp. 29-37, 2002.

[8] D. A. Saúde-Guimarães and A. R. Faria, "Substâncias da natureza com atividade anti-Trypanosoma cruzi," Revista Brasileira de Farmacognosia, vol. 17, no. 3, pp. 455-465, 2007.

[9] S. G. Andrade and J. B. Magalhães, "Biodemes and zymodemes of Trypanosoma cruzi strains: correlations with clinical data and experimental pathology," Revista da Sociedade Brasileira de Medicina Tropical, vol. 30, no. 1, pp. 27-35, 1996.

[10] A. Kanaujia, R. Duggar, S. T. Pannakal et al., "Insulinomimetic activity of two new gallotannins from the fruits of Capparis moonii," Bioorganic and Medicinal Chemistry, vol. 18, no. 11, pp. 3940-3945, 2010.

[11] K. Dodo, T. Minato, T. Noguchi-Yachide, M. Suganuma, and Y. Hashimoto, "Antiproliferative and apoptosis-inducing activities of alkyl gallate and gallamide derivatives related to (-)epigallocatechin gallate," Bioorganic and Medicinal Chemistry, vol. 16, no. 17, pp. 7975-7982, 2008.

[12] C. Locatelli, R. Rosso, M. C. Santos-Silva et al., "Ester derivatives of gallic acid with potential toxicity toward L1210 leukemia cells," Bioorganic and Medicinal Chemistry, vol. 16, no. 7, pp. 3791-3799, 2008.

[13] C. Locatelli, P. C. Leal, R. A. Yunes, R. J. Nunes, and T. B. Creczynski-Pasa, "Gallic acid ester derivatives induce apoptosis and cell adhesion inhibition in melanoma cells: the relationship between free radical generation, glutathione depletion and cell death," Chemico-Biological Interactions, vol. 181, no. 2, pp. 175184, 2009.

[14] M. C. C. Morais, S. Luqman, T. P. Kondratyuk et al., "Suppression of TNF- $\alpha$ induced NFKB activity by gallic acid and its semi-synthetic esters: possible role in cancer chemoprevention," Natural Product Research, vol. 24, no. 18, pp. 1758-1765, 2010.

[15] V. F. Ximenes, M. G. Lopes, M. S. Petrônio, L. O. Regasini, D. H. Siqueira Silva, and L. M. da Fonseca, "Inhibitory effect of gallic acid and its esters on 2,2' -azobis(2- amidinopropane)hydrochloride (AAPH)-induced hemolysis and depletion of intracellular glutathione in erythrocytes," Journal of Agricultural and Food Chemistry, vol. 58, no. 9, pp. 5355-5362, 2010.

[16] R. Rosso, T. O. Vieira, P. C. Leal, R. J. Nunes, R. A. Yunes, and T. B. Creczynski-Pasa, "Relationship between the lipophilicity of gallic acid n-alquil esters' derivatives and both myeloperoxidase activity and $\mathrm{HOCl}$ scavenging," Bioorganic and Medicinal Chemistry, vol. 14, no. 18, pp. 6409-6413, 2006.

[17] L. O. Regasini, D. C. Fernandes, I. Castro-Gamboa et al., "Chemical constituents of the flowers of Pterogyne nitens (Caesalpinioideae)," Quimica Nova, vol. 31, no. 4, pp. 802-806, 2008.

[18] I. Kubo, P. Xiao, and K. Fujita, "Antifungal activity of octyl gallate: structural criteria and mode of action," Bioorganic and Medicinal Chemistry Letters, vol. 11, no. 3, pp. 347-350, 2001.

[19] K.-I. Fujita and I. Kubo, "Antifungal activity of octyl gallate," International Journal of Food Microbiology, vol. 79, no. 3, pp. 193-201, 2002.

[20] P. C. Leal, A. Mascarello, M. Derita et al., "Relation between lipophilicity of alkyl gallates and antifungal activity against yeasts and filamentous fungi," Bioorganic and Medicinal Chemistry Letters, vol. 19, no. 6, pp. 1793-1796, 2009.

[21] I. Kubo, P. Xiao, and K. Fujita, "Anti-MRSA activity of alkyl gallates," Bioorganic and Medicinal Chemistry Letters, vol. 12, no. 2, pp. 113-116, 2002.

[22] I. Kubo, K.-I. Fujita, and K.-I. Nihei, "Molecular design of multifunctional antibacterial agents against methicillin resistant Staphylococcus aureus (MRSA)," Bioorganic \& Medicinal Chemistry, vol. 11, no. 19, pp. 4255-4262, 2003.

[23] L. H. P. Silva and V. Nussenzweig, "Sobre uma cepa de Trypanosoma cruzi altamente virulenta para o camundongo branco," Folia Clínica et Biologica, vol. 20, pp. 191-208, 1953.

[24] J. F. Fernandes and O. Castellani, "Growth characteristics and chemical composition of Trypanosoma cruzi," Experimental Parasitology, vol. 18, no. 2, pp. 195-202, 1966.

[25] S. Muelas-Serrano, J. J. Nogal, R. A. Martínez-Díaz, J. A. Escario, A. R. Martínez-Fernández, and A. Gómez-Barrio, "In vitro screening of American plant extracts on Trypanosoma cruzi and Trichomonas vaginalis," Journal of Ethnopharmacology, vol. 71, no. 1-2, pp. 101-107, 2000.

[26] F. Cotinguiba, L. O. Regasini, V. S. Bolzani et al., "Piperamides and their derivatives as potential anti-trypanosomal agents," Medicinal Chemistry Research, vol. 18, no. 9, pp. 703-711, 2009.

[27] A. Cossarizza, M. Baccarani-Contri, G. Kalashnikova, and C. Franceschi, "A new method for the cytofluorimetric analysis of mitochondrial membrane potential using the J-aggregate forming lipophilic cation 5,5'6,6'-tetrachloro- $1,1^{\prime}, 3,3^{\prime}$ tetraethylbenzimidazolcarbocyanine iodide (JC-1)," Biochemical and Biophysical Research Communications, vol. 197, no. 1, pp. 40-45, 1993.

[28] G. V. Kulkarni, W. Lee, A. Seth, and C. A. G. McCulloch, "Role of mitochondrial membrane potential in concanavalin A-induced apoptosis in human fibroblasts," Experimental Cell Research, vol. 245, no. 1, pp. 170-178, 1998.

[29] F.-L. Hsu, H.-T. Chang, and S.-T. Chang, "Evaluation of antifungal properties of octyl gallate and its synergy with 
cinnamaldehyde," Bioresource Technology, vol. 98, no. 4, pp. 734-738, 2007.

[30] J. K. Hellmann, S. Münter, M. Wink, and F. Frischknecht, "Synergistic and additive effects of epigallocatechin gallate and digitonin on Plasmodium sporozoite survival and motility," PLoS ONE, vol. 5, no. 1, Article ID e8682, 2010.

[31] J. A. Urbina, K. Lazardi, T. Aguirre, M. M. Piras, and R. Piras, "Antiproliferative synergism of the allylamine SF 86327 and ketoconazole on epimastigotes and amastigotes of Trypanosoma (Schizotrypanum) cruzi," Antimicrobial Agents and Chemotherapy, vol. 32, no. 8, pp. 1237-1242, 1988.

[32] J. A. Urbina, J. Vivas, G. Visbal, and L. M. Contreras, "Modification of the sterol composition of Trypanosoma (Schizotrypanum) cruzi epimastigotes by $\triangle^{24(25)}$-sterol methyl transferase inhibitors and their combinations with ketoconazole," Molecular and Biochemical Parasitology, vol. 73, no. 1-2, pp. 199-210, 1995.

[33] J. A. Urbina, J. L. Concepcion, S. Rangel, G. Visbal, and R. Lira, "Squalene synthase as a chemotherapeutic target in Trypanosoma cruzi and Leishmania mexicana," Molecular and Biochemical Parasitology, vol. 125, no. 1-2, pp. 35-45, 2002.

[34] J. A. Urbina, "Ergosterol biosynthesis and drug development for Chagas disease," Memórias do Instituto Oswaldo Cruz, vol. 104, no. 1, pp. 311-318, 2009.

[35] J. D. Ly, D. R. Grubb, and A. Lawen, "The mitochondrial membrane potential $(\Delta \psi \mathrm{m})$ in apoptosis; an update," Apoptosis, vol. 8, no. 2, pp. 115-128, 2003.

[36] W. de Souza, M. Attias, and J. C. F. Rodrigues, "Particularities of mitochondrial structure in parasitic protists (Apicomplexa and Kinetoplastida)," International Journal of Biochemistry and Cell Biology, vol. 41, no. 10, pp. 2069-2080, 2009.

[37] M. Sands, M. A. Kron, and R. B. Brown, "Pentamidine: a review," Reviews of Infectious Diseases, vol. 7, no. 5, pp. 625-634, 1985.

[38] A. E. Vercesi and R. Docampo, " $\mathrm{Ca}^{2+}$ transport by digitoninpermeabilized Leishmania donovani. Effects of $\mathrm{Ca}^{2+}$, pentamidine and WR-6026 on mitochondrial membrane potential in situ," Biochemical Journal, vol. 284, no. 2, pp. 463-467, 1992.

[39] S. L. Croft and R. P. Brazil, "Effect of pentamidine isethionate on the ultrastructure and morphology of Leishmania mexicana amazonensis in vitro," Annals of Tropical Medicine and Parasitology, vol. 76, no. 1, pp. 37-43, 1982.

[40] B. Hentzer and T. Kobayasi, "The ultrastructural changes of Leishmania tropica after treatment with pentamidine," Annals of Tropical Medicine and Parasitology, vol. 71, no. 2, pp. 157-166, 1977.

[41] I. Abe, T. Seki, and H. Noguchi, "Potent and selective inhibition of squalene epoxidase by synthetic galloyl esters," Biochemical and Biophysical Research Communications, vol. 270, no. 1, pp. 137-140, 2000.

[42] W. de Souza and J. C. F. Rodrigues, "Sterol biosynthesis pathway as target for anti-trypanosomatid drugs," Interdisciplinary Perspectives on Infectious Diseases, vol. 2009, Article ID 642502, 19 pages, 2009.

[43] K. E. Bloch, "Sterol structure and membrane function," CRC Critical Reviews in Biochemistry, vol. 14, no. 1, pp. 47-92, 1983.

[44] A. Arora, H. Raghuraman, and A. Chattopadhyay, "Influence of cholesterol and ergosterol on membrane dynamics: a fluorescence approach," Biochemical and Biophysical Research Communications, vol. 318, no. 4, pp. 920-926, 2004.

[45] E. Zinser, C. D. M. Sperka-Gottlieb, E.-V. Fasch, S. D. Kohlwein, F. Paltauf, and G. Daum, "Phospholipid synthesis and lipid composition of subcellular membranes in the unicellular eukaryote
Saccharomyces cerevisiae," Journal of Bacteriology, vol. 173, no. 6, pp. 2026-2034, 1991.

[46] N. Mbongo, P. M. Loiseau, M. A. Billion, and M. Robert-Gero, "Mechanism of amphotericin B resistance in Leishmania donovani promastigotes," Antimicrobial Agents and Chemotherapy, vol. 42, no. 2, pp. 352-357, 1998.

[47] K. Lazardi, J. A. Urbina, and W. de Souza, "Ultrastructural alterations induced by two ergosterol biosynthesis inhibitors, ketoconazole and terbinafine, on epimastigotes and amastigotes of Trypanosoma (Schizotrypanum) cruzi," Antimicrobial Agents and Chemotherapy, vol. 34, no. 11, pp. 2097-2105, 1990.

[48] Z. J. Molina-Garza, A. F. Bazaldúa-Rodríguez, R. QuintanillaLicea, and L. Galaviz-Silva, "Anti-Trypanosoma cruzi activity of 10 medicinal plants used in northeast Mexico," Acta Tropica, vol. 136, no. 1, pp. 14-18, 2014. 


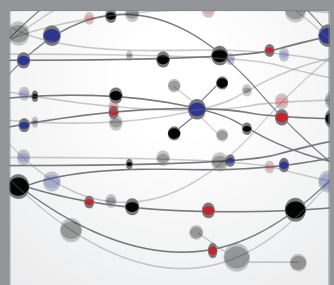

The Scientific World Journal
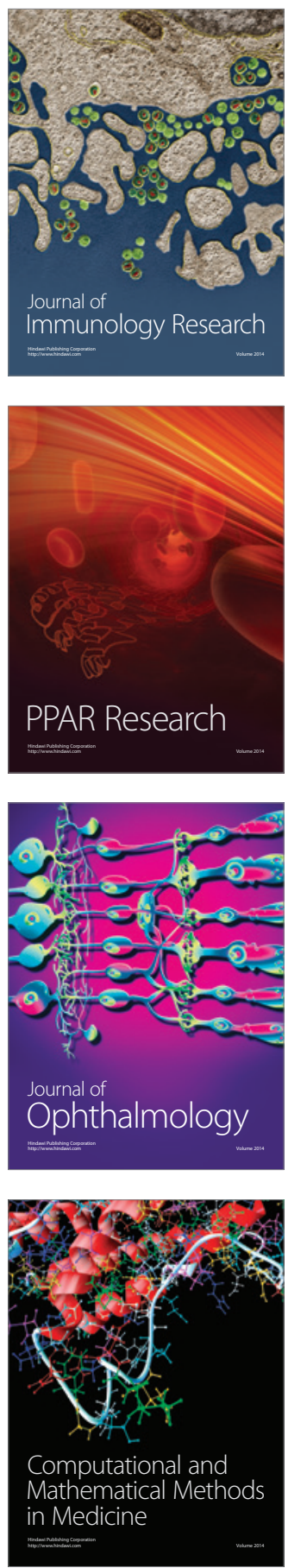

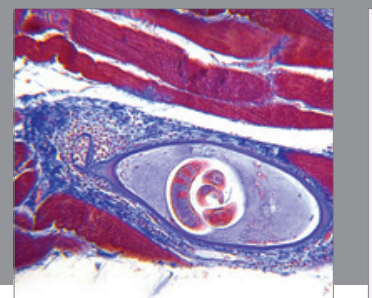

Gastroenterology

Research and Practice
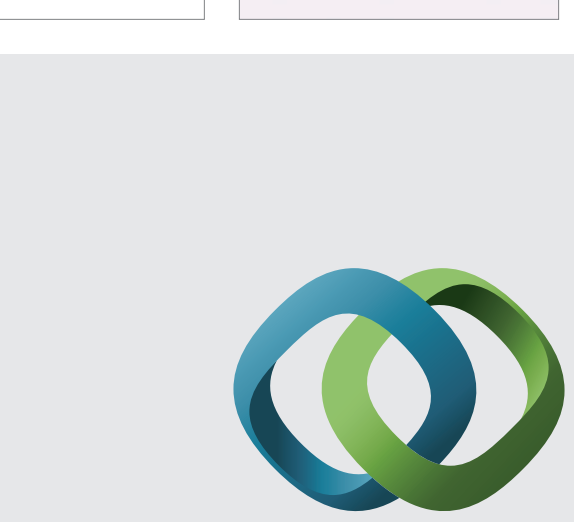

\section{Hindawi}

Submit your manuscripts at

http://www.hindawi.com
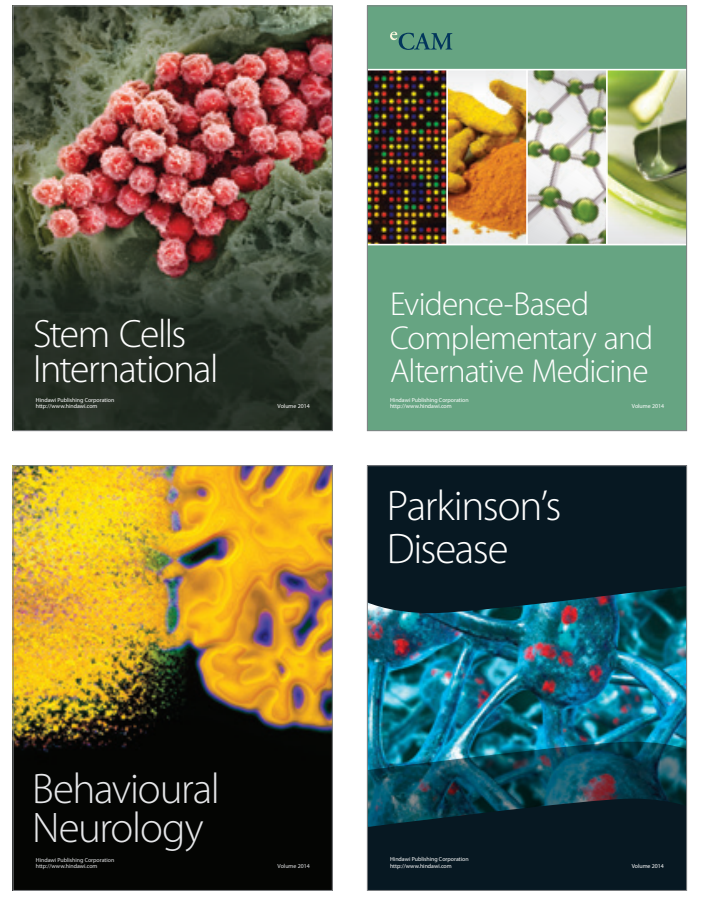
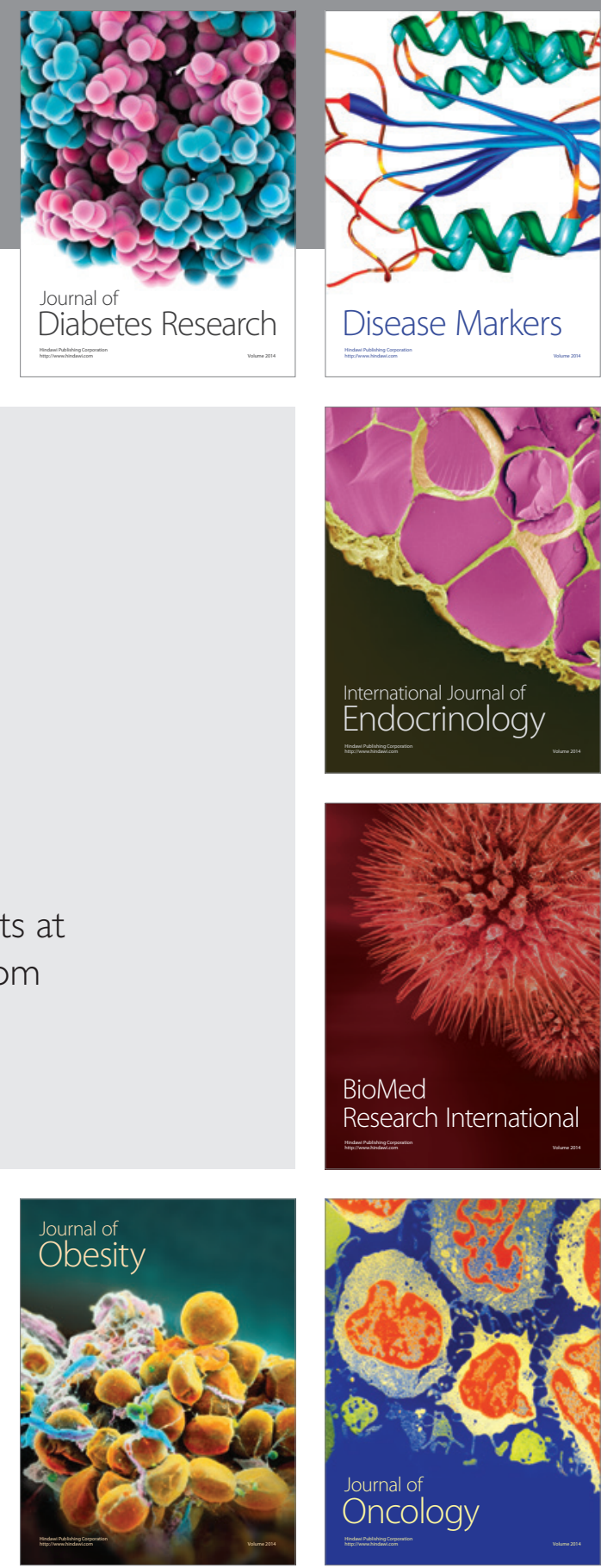

Disease Markers
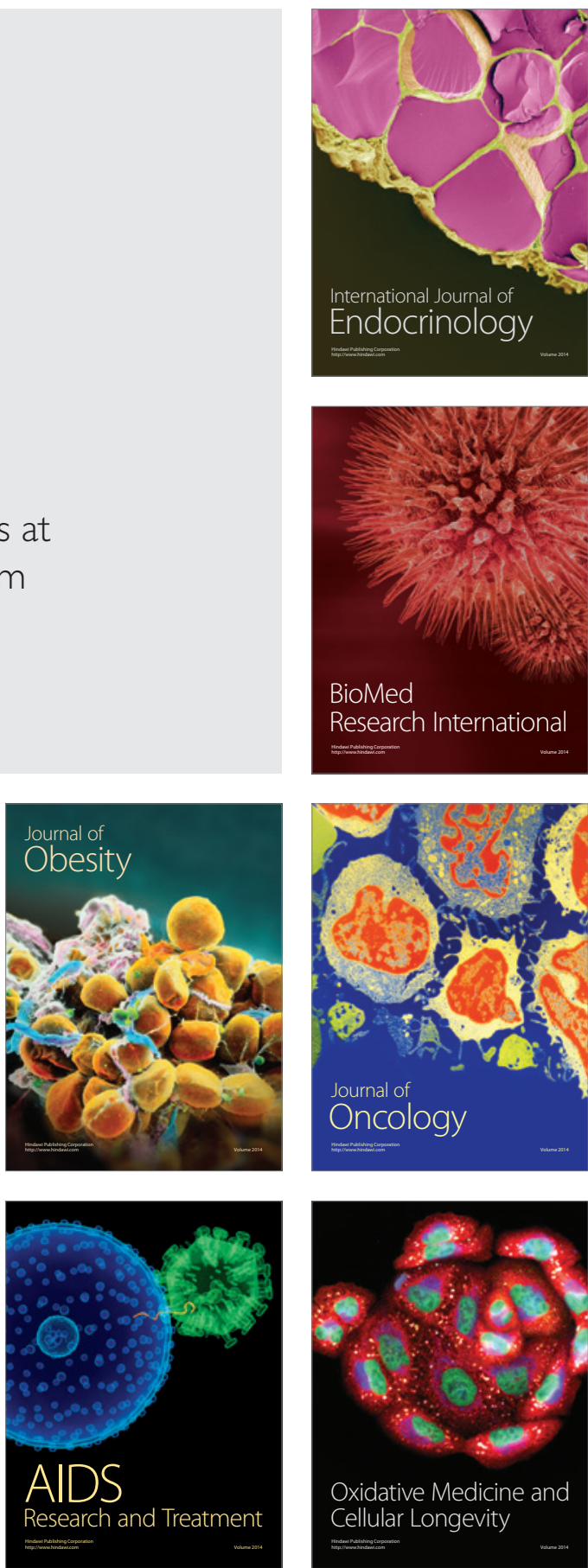